\title{
Metodologia jurídica e internacionalização dos contratos
}

Joaquim Renato Correa Freire, advogado especialista em direito internacional.

A montagem contratual tem que começar pelo problema das definições no contrato. Por exemplo, logo de início será necessário definir o que seja a força maior, definir hardship clause de maneira completa, para que se evitem controvérsias futuras. Outras definições também são importantes; não é apenas por consistência e abreviação que elas são feitas, é necessário algümas vezes precisar bem o objeto do contrato. Calculem vocês, por exemplo, quando estamos falando numa garantia, estamos falando de obrigações. Ora, a palavra "obrigações", usada livremente num contrato, pode trazer uma série de problemas. É preciso definir o que seja obrigações, dentro do contexto do contrato.

Outra palavra, por exemplo, que precisa ser muito bem-definida, principalmente em contratos com o Estado, é o termo government ou aid, agências governamentais que podem significar apenas - Estado contratante, pode significar entes autárquicos do Estado contratante, mas pode também significar empresas públicas e empresas mistas. Portanto, é preciso definir, e essas definições devem aparecer, necessariamente, logo após o preâmbulo dos contratos.

Depois, tem-se o problema da descrição do empréstimo e também da destinação dos fundos. Vejam aqui uma referência mais a um contrato de mútuo internacional do que dos contratos envolvendo projetos financeiros, o projeto financiado, ou outros contratos porque, na realidade, sobre eles já falamos muito nas sessões anteriores. Portanto eu preferi usar como exemplo um contrato de mútuo internacional.

\section{Joaquim Renato Corrêa Freire}

Na descrição do empréstimo, que é de uma certa maneira muito influenciada no Brasil pelo dirigismo do Banco Central do Brasil, já que estão lá todas as condições financeiras que têm que ser aprovadas pelo Banco Central, é preciso que se diga exatamente como o empréstimo se descreve, a forma de desembolso, etc., e também, em alguns casos, muito importante é saber a destinação específica do empréstimo; este é um pré-requisito essencial do project financial; não é tanto um requisito essencial de um contrato de mútuo internacional, mas costuma-se também precisar o que seja o que nós conhecemos como use of the peril, isto é, para quem o empréstimo se destina e em que o tomador vai empregar as quantias tomadas emprestadas. Esse problema pode ser fundamental, como nós vemos, porque muitas yezes o use of the fervil o uso do empréstimo pode ser considerado como uma forma de inadimplemento técnico. É muito importante que se descreva o the use of the percil ou o uso do resultado do empréstimo logo no preâmbulo do contrato. Depois nós temos o que nós chamamos de conditions of lauding, ou as condições precedentes ao desembolso. É evidente que a condição essencial para que haja desembolso é a assinatura do contrato e que o contrato esteja pronto e assinado pelas partes antes que qualquer quantia seja desembolsada. Depois, evidentemente, os documentos que compõem o contrato, como as notas promissórias, as eventuais garantias ou um contrato separado de garantia que, muitas vezes, aparece, e, também, muito importante são as opiniões dos advogados, são as conhecidas liga lupius. Normalmente há o advogado do tomador do país sobre a lei que regula o con- 
trato, há a opinião do advogado do emprestador; no Brasil, há opinião do advogado do garantidor e às vezes pode haver até uma outra opinião legal, independente, para cada uma das partes do contrato. Todas essas opiniões são pré-requisitos para que o empréstimo seja efetuado e devem ser apresentadas antes do chamado closing, ou fechamento do contrato.

Essas opiniões legais, a meu ver, são muito importantes; elas não devem ser dadas pelos advogados apenas como uma providência burocrática dentro da montagem contratual; o advogado deve examinar profundamente todas as circunstâncias que envolvem esse tipo de financiamento, exaustivamente, eu diria, e dar a sua opinião da maneira mais completa possível, qualificando-a, inclusive, quando necessário.

Depois dessas condições precedentes ao desembolso, nós temos o que se descreve em inglês por representation and warrants, que são declarações de fatos afirmados como tais pelo tomador e pelo garantidor. Elas são afirmações de várias naturezas. Por exemplo, o tomador desde logo tem que representar sobre a sua natureza jurídica.

Depois, também, sobre os poderes que as partes, representando o tomador, têm para assinar o contrato. Eas notas promissórias que quase sempre estão juntas ao contrato. Eexistem muitas outras representações que são feitas afirmativamente como, por exemplo, de que as condições financeiras do empréstimo foram aprovadas pelo Banco Central do Brasil e que a operação esteja credenciada, como é dito atualmente, e outras de natureza mais especifica, como por exemplo, a cláusula de pari passu, isto é, que aquele empréstimo segue, pari passu, da mesma forma que outros empréstimos que o tomador haja recebido.

Depois de se iniciar a famosa representação do que se chama de notrasse, isto é, que não existem ações judiciais propostas ou por serem propostas, que possam adversamente afetar as condições financeiras do tomador ou do garantidor.

Finalmente, há algumas representações sobre impostos, e nos contratos de convênio com o Estado há sempre a menção ao problema da soberania ou, se for o caso, de uma exceção à soberania, world no soberant, que se segue dentro dessas representações. Após os representations and warrants, nós costumamos encontrar os covennants, que nada mais são do que a maneira de manter válidas as representations and warrants, através de práticas positivas ou negativas. Na realidade, olhando os covennants, do aspecto do direito brasileiro, do nosso direito obrigacional, nada mais são do que obrigações de fazer ou não fazer, que os tomadores e garantidores assumem para dar validade e permanência às representations and warrants. Segue-se o famoso problema do inadimplemento ou do events of defaults. Há que distinguir três tipos de defaults. Acho que sobre isso já falamos alguma coisa aqui, mas poderemos voltar a falar ainda hoje: o monetary defaults, o technical defaults e, finalmente, muito importante também, o chamado clause default.

O default monetário ou o inadimplemento típico é, como todos sabemos, a falta de pagamento do principal, dos juros, ou de alguma das taxas previstas no contrato. Não há grandes problemas quanto à observação desse default típico, que é a falta de pagamento.

Entretanto, os defaults técnicos precisam ser muito bem-especificados porque sobre eles é que realmente surgem as maiores divergências em termos de controvérsias em contratos de empréstimos internacionais. É preciso que o technical default seja muito bem descrito porque, muitas vezes, como no caso da hardship, que o dr. Luiz Olavo explicou tão bem, ele pode ser curado. Outras vezes o technical default não é curável e causa a rescisão do contrato. Portanto, esses technical defaults são muito importantes e devem ser bem-definidos no contrato.

Dentro desses technical defaults nós podemos distinguir dois: um que constitui apenas um default, mas que não causa a aceleração da dívida, outro que causa a aceleração da dívida. Estes são ainda mais importantes pois, se há um default técnico que causa a aceleração da dívida, esse default torna-se, automaticamente, um default monetário. Portanto, esse tipo de default técnico que causa a aceleração precisa ser muito bem-descrito e fazer entre os dois, 0 que causa e o que não causa a aceleração, uma distinção muito bem-elaborada.

Finalmente, a clouse default. Esta é realmente uma cláusula de que o tomador tem muito medo, e com boas razões porque, na realidade, pode implicar que um inadimplemento em outro qualquer contrato assinado por esse tomador cause um default dentro do próprio contrato.

Ora, empresas que contratam um ou outro empréstimo durante um exercício social não têm problemas com esse clouse default. Mas quando o tomador é uma empresa enorme, ou o próprio Estado, ou uma empresa de economia mista, ou uma empresa estatal direta, aí temos sérios problemas.

A Procuradoria da Fazenda Nacional, da qual o dr. Luiz Americano é o ilustre representante, tem sido muito atenciosa nesta questão das clouse defaults, quando a República ou uma de suas empresas aparecem como tomadora ou garantidora porque, na realidade, um clouse default pode antecipar muito uma quantidade enorme de compromissos da nossa dívida externa, quando não, praticamente to- 
da a dívida externa por um default apenas em um contrato. De maneira que essa clouse default é realmente para as empresas públicas e a República uma preocupação muito constante.

Depois do representation and warrant nós poderíamos passar para algumas cláusulas mais específicas, e muito mais do nosso interesse como juristas e advogados. Entretanto, eu gostaria de fazer apenas pequena menção ao problema do set of, ou da compensação. Era comum até pouco tempo, em contratos firmados pelas partes e não pelo Estado, que se colocasse uma cláusula de set of que dava ao credor a possibilidade de compensar créditos havidos contra o tomador, em outros contratos, ou por outras diferentes circunstâncias. Muitas dessas empresas operam no exterior e, portanto, seria dada ao credor a possibilidade de usar disponibilidades em seu poder, pertencentes às empresas tomadoras, compensando eventuais débitos daquele contrato. Esse probiema do set of foi afastado pela Procuradoria da Fazenda Nacional, pois constituía, ao ver da Procuradoria, uma infração a duas leis brasileiras: a lei de remessas de lucros e também o problema do controle pelas nossas autoridades monetárias das operações de câmbio. Mas, recentemente, um parecer da Procuradoria, do qual foi dado conhecimento ao Banco Central, depois de aprovado pelo ministro da Fazenda, proibiu o set of em todos os tipos de transação, alegando que essa disposição era contra o interesse nacional, não só por infringir o problema cambial, mas também por infringir as nossas antigas leis cambiais, aquelas que advêm desde os tempos da cláusula-ouro. Portanto, esses são os problemas, vamos dizer assim, mais cruciais na montagem contratual básica que às vezes aparecem e são chamados de bailer flait, isto é, eles vêm assim dos advogados americanos como um todo e muitas vezes a gente tem quase que concordar. Não é o caso. Muitas e muitas vezes eu instituí, e meus colegas sempre fazem isso, inúmeras adaptações a esses tipos de cláusulas, discutindo-as com o Banco Central, com a Procuradoria da Fazenda Nacional, quando é o caso, e também com os advogados dos tomadores. De maneira qua acho que já se foi o tempo em que no Brasil aceitávamos contratos de empréstimos com cláusulas bailer-flait. Isto não ocorre mais e os nossos colegas estrangeiros aqui sabem disso.

O problema da lei aplicável aos contratos de empréstimos internacionais, embora pudesse causar igualmente importantes dúvidas e debates, tem sido resolvido surpreendentemente, e através de pacífica acomodação. Isto tem acontecido principalmente por dois motivos: o primeiro porque quase todos os países do mundo adotaram o sistema de liberdade contratual absoluta nas suas normas internas e de direito internacional privado, como são aquelas entre nós incluídas na Lei de Introdução ao
Código Civil. Existem limitações a essa liberdade e as mesmas devem ser expressas em lei.

A segunda, deriva do fato de que, com raras exceções, o direito obrigacional dos vários sistemas legais existentes na atualidade oferecem, de uma maneira ou de outra, adequada proteção às partes contratantes. Não tem sido difícil, portanto, chegar a um consenso à lei aplicável: pode ser a do credor, a do devedor ou de um terceiro, o Estado.

Por outro lado, como em quase todas as negociações jurídicas que resultam em contratos internacionais de empréstimos ou financiamentos, o problema da lei aplicável é expressamente tratado e a escolha da lei é livremente feita pelas partes, o espaço para controvérsias é reduzido ao mínimo; contudo esse mínimo existe quando da falta de estipulação contratual. A maioria das normas de direito internacional privado, prevêem nestes casos que a lei aplicável será a do país do proponente. Nos casos de empréstimo entende-se, pois, que a lei do país da parte que deu início às negociações, dependendo da circunstância de ser a negociação iniciada por aquele interessado em receber o mútuo ou aquele em concedê-lo. Constituem essas hipóteses, entretanto, raríssimas exceções já que no universo sofisticado das contratações e empréstimos internacionais não cabem lacunas, no que diz respeito à determinação da lei aplicável. Os contratos prevêem expressamente a adoção daquilo que melhor se aplique aos interesses das mesmas partes. Em outras palavras, existe a plena liberdade contratual, mas tem-se o cuidado de observar a predeterminação expressa para evitar inúteis controvérsias.

A jurisprudência não nos dá notícia de qualquer importante litígio, com relação à lei aplicável, no que diz respeito à contratação ou à execução de empréstimos internacionais. Aqui convém lembrar o seguinte: quanto à lei aplicável - nós estamos falando, portanto, de uma opção pela lei nacional ou pela lei do lugar onde o contrato vai ser executado ou por uma outra lei eleita pelas partes, de qualquer maneira, é uma opção por uma lei de algum país.

Entretanto, existe uma tendência atual, principalmente depois de alguns estudos feitos na Universidade de Harvard, sobre a internacionalização do contrato, de que os contratos de empréstimo internacional poderiam ser regidos por normas de direito internacional. Pois bem, esse tipo de discussão aflora o problema da internacionalização do contrato, que nós discutiremos ao término, mas, antes disso, eu queria dizer apenas brevemente alguma coisa sobre a arbitragem, mas com um pequeno cavern.

Vou fazer aqui, sobre a arbitragem, um mero e pequeno report, sem outras intenções, porque, no último seminário, eu expus uma tese de alguns ju- 
ristas, aos quais eu me filio e que, de alguma forma, iam contra a propositura da arbitragem para todas as controvérsias do direito internacional, principalmente num contrato de mútuo em que eu não vejo muito o que há por arbitrar, a não ser aquele problema das definições ou o que seja o default técnico. Mas, como naquele seminário, houve aqui um debate acalorado sobre o problema, eu preferia deixar que ele ocorresse no painel, servindo eu aqui como mero expositor do que significa arbitragem nos contratos de mútuo principalmente no Brasil.

A arbitragem internacional é um outro modo pelo qual as partes, em um contrato de empréstimo externo exercendo a liberdade de escolha a que nos referimos anteriormente, têm utilizado para por termo a eventuais disputas privadas oriundas do contrato. Entretanto, a arbitragem, um procedimento que teve ampla aceitação no passado para a solução de conflitos no direito comercial internacional, não tem sido muito utilizada no que diz respeito a empréstimos. A dificuldade e a pouca utilização derivam de dois principais fatores: o primeiro, porque os banqueiros internacionais desenvolveram um conceito segundo o qual, no que diz respeito a um empréstimo, não há nada realmente o que arbitrar; ou o tomador cumpre a obrigação no que diz respeito ao serviço da dívida e ao montante do principal ou deixa de cumpri-lo. No segundo caso, verifica-se o inadimplemento. O remédio adequado, segundo os banqueiros, é o imediato ingresso em juízo, constituindo a cláusula arbitral, na verdade, quando existente, um procedimento que retarda a solução do conflito, pois, na maioria dos casos, a jurisdição dos tribunais locais ou outros eleitos pelo contrato, tem sido preferida, em que pesem os problemas de soberania.

O segundo fator diz respeito à falta de celeridade processual observada nas decisões arbitrais. Conquanto os tribunais possam ser formados rapidamente e chegar a uma decisão também com relativa celeridade, a execução de um laudo arbitral é extremamente demorada, para não dizer penosa.

De fato, muitas legislações, como a brasileira atual, prevêem certas formalidades legais para a instituição da arbitragem, que é o compromisso arbitral. Além disso, muitas legislações, e a nossa é um exemplo típico, não reconhecem um juízo arbitral perfect. Precisa ele, pois, ser homologado por um tribunal competente do lugar e do país onde se realizou a arbitragem.

Por sua vez, a decisão do tribunal estrangeiro terá, no caso do Brasil, que ser homologado perante o Supremo Tribunal Federal, e só depois da homologação poderá ser executada por um tribunal de jurisdição competente.
Nesse ponto quero remetê-los aos Anais do nosso seminário anterior, pois que naquele nós discutimos pormenorizadamente, uns a favor e outros contra, a possibilidade de uma specific performan$c e$, isto é, de uma execução específica do laudo arbitral no Brasil, por força de estar ainda em vigor a Convenção de Genebra de 1923, sobre Arbitragem Internacional, da qual o Brasil fez parte e ratificou expressamente. Entretanto, muitos juristas brasileiros, aos quais me filio, não são adeptos dessa teoria da aplicação automática e específica da Convenção de Genebra.

Deixo aos eminentes debatedores a ingrata função de dirimir essa controvérsia. De qualquer modo, o juízo arbitral ainda é, às vezes, utilizado para decidir pendências relativas a empréstimos internacionais. O Banco Mundial, por exemplo, através do Commencional of Investiment Between States deu causa à criação do Internacional Center Investiments, tem sido, em muitos casos, escolhido por emprestadores e tomadores na contratação de empréstimos internacionais.

Uma outra escolha freqüente é o Tribunal Permanente de Arbitragem da Câmara de Comércio de Paris, França, e outros tantos espalhados pelo mundo. No Brasil, o juízo arbitral, pelos motivos expostos e pelas próprias dificuldades criadas pelo atual Código de Processo Cívil, tem sido pouquíssimo utilizado. Temos em São Paulo a Câmara de Comércio Brasil-Canadá que possui um Tribunal Permanente de Arbitragem, até com uma regulamentação muito sofisticada, mas que eu saiba até hoje nunca foi usado.

Recentemente, o ministro da Justiça submeteu à apreciação dos interessados um anteprojeto de lei sobre arbitragem. Algumas das disposições desse anteprojeto resolvem ou tentam resolver, em parte, a questão do specific performance do laudo arbitral prolatado no exterior.

Falta apenas dizer duas coisas: quando o Brasil é parte de um contrato de mútuo internacional, tem adotado a tese da soberania absoluta, isto é, ele não abre mão da sua soberania de serem acionados no seu foro competente, que é o Brasil, os tribunais federais brasileiros. Entretanto, essa soberania absoluta pode tornar-se relativa quando se trata de um ente governamental, uma empresa mista ou uma empresa do Estado e, portanto, essa matéria tem sido considerada com muito cuidado pela Procuradoria da Fazenda Nacional. Vejam vocês que tudo isso nos devolve a um tema central: se nos contratos de mútuo internacional nós começamos a falar de arbitragem e da possível aplicação de normas do direito internacional, do general principal of international law, nós estamos adentrando na tese da internacionalização dos contratơs. 
Ora, muitos juristas do Terceiro Mundo levantam-se contra essa tese da internacionalização dos contratos, pois alegam que essa internacionalização dá margem a que empresas multinacionais tenham uma certa preponderância na negociação contra pequenos Estados ou mesmo contra pequenas empresas do governo de determinado país. O prof. Marcelo Hulkes, da Faculdade de Direito da Universidade de São Paulo, em tese recente, levantou-se contra essa posição dizendo que a internacionalização do contrato estaria contra os países em desenvolvimento. Eu não penso assim; não penso porque os países em desenvolvimento, eé por isso que nós estamos aqui, também estão contratando no exterior, e muito, e também com países do mesmo ranking, em desenvolvimento, ou até menos desenvolvidos do que nós.

Acreditamos que a aplicação apenas da lei do país com que o Brasil vai negociar, por exemplo, na África, pode não ser a melhor forma. Portanto, a arbitragem internacional e até mesmo os princípios gerais do direito internacional podem interessar ao Brasil. Essa questão merece ser examinada com cuidado, é uma questão de política do direito ou do direito por fazer sobre a qual convido à reflexão.

\section{Domínio da lei, nascimento, extinção e inexecução das obrigações no contrato internacional}

\author{
Frederico José Straube, chefe do \\ Departamento Jurídico da Hidroservise, \\ Engenharia de Projetos Ltda.
}

Frederico José Straube
O princípio da competência geral da lei do contrato terá abrangência maior ou menor, dependendo do que se entenda exatamente pela expressão "efeitos do contrato". Sem determinação da noção de efeitos do contrato, não tem maiores repercussões, no plano interno. A precisão torna-se essencial no plano internacional, na medida em que sua análise pode conduzir a conseqüências jurídicas diferentes. Caso a expressão "efeitos do contrato" seja tomada em um sentido tão amplo, de modo a que ela compreenda todos os atos que estejam ligados à operação contratual, desde a criação do liame obrigacional até o desaparecimento total da situação contratual, parece duvidoso que a competência da lei do contrato seja geral. O princípio da competência da lei do contrato não sofre maiores contestações no que concerne à criação mesmo do liame obrigacional, ou seja, no que diz respeito à força obrigatória do contrato. É, porém, no que tange à execução do contrato que as objeções feitas à competência da lei contratual têm sido mais vivas. Os argumentos que embasam tais objeções não têm senão valor limitado, visto que a unidade da operação contratual determina, em longa medida, a aplicação da lei segundo a qual a validade do contrato foi apreciada, ou seja, a lei do contrato. A solução parece se impor, também, ainda que sob certas reservas, quando se trata de determinar as conseqüências da inexecução do contrato que são ligadas ao princípio da força obrigatória do contrato. No exame da delimitação do domínio da lei do contrato enfocaremos o assunto sob três aspectos diferentes, conforme já havia salientado, embora sejam eles correlatos: o primeiro concerne às obrigações das partes; o segundo diz respeito à execução do contrato; o terceiro se refere às conseqüências da inexecução do contrato.

A lei do contrato determina, em princípio, a extenção das obrigações criadas pelo contrato a cargo de uma e de outra parte ou das duas, quando o contrato é sinalagmático. Este princípio, em grande medida, deverá permitir igualmente fixar a duração dessas obrigações.

Dois pontos devem ser enfocados quando se trata da extensão das obrigações: de um lado a determinação das obrigações nascidas do contrato e, de outro lado, a modificação destas em função de circunstâncias posteriores à conclusão do contrato. A determinação das obrigações nascidas do contrato e de seu conteúdo, demandam alguns comentários, pois é evidente que a insuficiência de estipulação das partes acarreta a necessidade de suplementação, fundadas em disposições de um sistema legal positivo. Da mesma forma que a lei aplicável ao 